\title{
THE EFFECT OF YEAST ON THE ANTHOCYANIN CHARACTERISTICS OF FERMENTED MODEL SOLUTIONS
}

\author{
A. LeSkó*a ${ }^{* a}$ D. Nyitrai-SÁrdYa ${ }^{\mathrm{a}}$ M. KÁllaY ${ }^{\mathrm{a}}$ and I. BALGA ${ }^{\mathrm{b}}$ \\ a Department of Oenology, Institute of Viticulture and Oenology, Corvinus University of Budapest, \\ H-1118 Budapest, Ménesi út 45. Hungary \\ ${ }^{\mathrm{b}}$ Institute of Agrotechnology, Károly Róbert College, H-3200 Gyöngyös, Mátrai út 36. Hungary
}

(Received: 4 October 2012; accepted: 3 January 2013)

\begin{abstract}
The sensory quality of red wines is basically determined by the colour, which depends on the amount and on the evolution of anthocyanins and other phenolic compounds extracting from the berries into the wine during winemaking. The anthocyanin-monomers are responsible for the development of the red colour, and their acylated derivatives provide stability for the colour of the wines. The anthocyanin profile of wines is affected by several factors: the grape variety, the conditions during wine-making, and also the yeast culture used for the fermentation. In our experiments a self-compiled model solution was fermented by spontaneous fermentation, as well as by four commercial yeasts under laboratory conditions. After fermentation total polyphenolics, anthocyanins, anthocyanin monomer profile, colour intensity, hue, and the ratio of polymeric anthocyanins were studied. Our results show that the spontaneous yeast fermentation resulted in a higher anthocyanin concentration in the fermented model solution, but the commercial yeast strains provided a more advantageous colour characteristic compared to the spontaneous fermentation. After the spontaneous fermentation less sediment was left than in the commercial yeast fermented samples.
\end{abstract}

Keywords: anthocyanin profile, commercial yeast

The enzyme activity of yeasts might evoke various side reactions (malo-alcoholic fermentation, $\beta$-glycosidase activity, tyrosol production, etc). Starter cultures significantly affect the polyphenolic structure, especially in the context of red wine (fermented on skins). The manufacturers and distributers give detailed information about the mechanism attributed to them.

Is there any change in the composition and in the concentration of anthocyanins when different starter yeast strains are applied, how do the polyphenol components (catechin, leucoanthocyanins, resveratrol, etc.) change? It is legitimate to ask these questions even if we know that the "gentleness" of the different pieces of wine-making equipment is an important aspect of the amount of the "sediment". Therefore, the effect of several commercially available yeasts, which are recommended for red wine fermentation, on the anthocyanin profile and on other polyphenolic ingredients were examined.

The characteristic and the colour of red wines are essentially determined by the amount of red grape pigments (anthocyanins and other phenolic compounds) produced during ripening. In terms of the grape the anthocyanin composition - especially their acylated derivatives - may be characteristic of the variety and the cultivation method (REviLLA et al., 2001), which is only slightly affected by vintage factors. Evidently, the situation is different in the case of wine. During the first third of the technological period of red wine fermentation

\footnotetext{
* To whom correspondence should be addressed.

Phone: +36 1482 6216; fax: +3614826347; e-mail: annamaria.lesko@uni-corvinus.hu
} 
anthocyanins are "dissolved", extracted, i.e. anthocyanin-monomers quickly reach their maximum concentration in the fermenting medium.

In the European Vitis cultivars around 10 heterosides of anthocyanins can be identified, which are monoglycosides and their acylated derivatives. In acylated derivatives acetic acid or para-coumaric acid is attached to the anthocyanin molecule. The acylated derivatives are largely responsible for the wine colour stability (MedinA et al., 2005).

\section{Interactions between the yeast cell and the anthocyanins}

The anthocyanin diffusion from the berry skin to the must comes through the molecular structure of the anthocyanins, which is determined by the variety, no matter whether the diffusion kinetic is influenced by the formed acetaldehyde, ethanol, and other fermentation products concentration or not (Di STEFANO et al., 1994).

The alcoholic fermentation is engined by the yeasts, which have different properties the main goal is to transform the sugar into alcohol during fermentation - and next to ground material they ultimately determine the final composition (including quality) (FLEET, 1999). Concerning the impact of yeasts on anthocyanins, they are capable of affecting the anthocyanin composition of wine: through their specific anthocyanase-activity the anthocyanin-glycosides are hydrolysed and they adsorb the anthocyanin monomers on their cell wall. According to the experiments of MORATO and co-workers (2003) and CHASSAGNE and colleagues (2005), the acylated anthocyanin monomers - acetates, coumarates - are strongly adsorbed on the yeast cell wall.

CUINIER (1988) found that the phenolic composition of wines is essentially influenced by the yeast, but also the amount of the absorbed red wine pigments on the yeast cell surface removed from the wine while racking can be an important factor. Studies on Spanish regional yeasts have established that the acylated anthocyanins have a higher affinity to settle on the yeast cell wall (MORATO et al., 2003). The starter yeast cultures provide more intense colour and higher polyphenol concentration (BAUTISTA-OrTIN et al., 2007), but the interactions between the variety and the applied starter culture can also influence the colour of red wines (SIDARI et al., 2007).

\section{Materials and methods}

In this experiment a model solution was fermented by four different commercially available yeast cultures and by spontaneous fermentation. The brand names of the used yeast strains and their manufacturers are available at the authors.

The following strains were used:

S: spontaneous inoculation

A: Saccharomyces cerevisiae starter culture for the fermentation of Cabernet wines

B: Saccharomyces cerevisiae starter culture for red wines rich in flavour, colour and tannin

C: Saccharomyces cerevisiae var. bayanus starter for the production of wines with stable colour and fruity character

D: Saccharomyces cerevisiae var. cerevisiae starter culture for Bordeaux type red wines

The model solution was composed of 2.61 concentrated must (64\% ref), 1.31 teinturier (Ancellotta), 6.11 water, and $3 \mathrm{~g}$ yeast nutritive (Uvavital, Danstar Ferment AG). The analytical composition is as follows: $6.2 \mathrm{~g} \mathrm{l}^{-1}$ titratable acids, $1214 \mathrm{mg} \mathrm{l}^{-1}$ total polyphenolics, 
$245 \mathrm{mg} \mathrm{l}^{-1}$ anthocyanins with $32.9 \%$ polymerization degree, $1354 \mathrm{mg} \mathrm{l}^{-1}$ leucoanthocyanins, $791 \mathrm{mg} \mathrm{l}^{-1}$ catechins, 4.3 colour intensity, and 0.93 colour hue.

The model solution was divided into 15 equal portions. The fermentation was processed in three parallels for each yeast culture. For data analysis the average results of the parallel experiments were used.

The total polyphenolics content was measured using the method of SinGLETON and Rossi (1965) with Folin-Ciocalteu phenol reagent and expressed as gallic acid equivalent. The anthocyanin content was examined by the Ribereau-GAyon and StONESTREet (1965) method. The colour intensity, colour hue, and polymer ratio were defined from the $520 \mathrm{~nm}$ and $420 \mathrm{~nm}$ wavelength absorbance of the wines directly and after treatment with $20 \%$ sulphurous acid ( $0.1 \mathrm{ml}$ sulphurous acid added to $5 \mathrm{ml}$ of wine).

The qualitative and quantitative determinations of anthocyanin-monomers were carried out by the method of KÁlLAY and TuSNÁDY (2001) described below. The separation and quantification of components were done on the basis of calibration with commercially available standards (Carl Roth $\mathrm{GmbH} \& \mathrm{Co}$. KG). The wine samples were filtered through $0.45 \mu \mathrm{m}$ Sartorius membrane prior to injection into the device.

The circumstances of the anthocyanin-monomers determination and the settings of the chromatograph were: HP Series 1050 HPLC-device and detector; ODS Hypersil C18 $(100 \times 4.6 \mathrm{~mm}, 5 \mu \mathrm{m})$ column; $0,5 \mathrm{ml}$ per minute flow; $25^{\circ} \mathrm{C}$ temperature; $520 \mathrm{~nm}$ wavelength. Eluents: solution \#1: $50 \mathrm{mM}$ ammonium-phosphate $\mathrm{pH}=2.6$; solution \#2: $20 \%$ 'solution \#1' $+80 \%$ acetonitrile; solution \#3: $0.2 \mathrm{M} \mathrm{H}_{3} \mathrm{PO}_{4} \mathrm{pH}=1.5$.

The determination was done by gradient elution as follows: $8 \%$ "solution \#2" and $92 \%$ "solution \#3" at the beginning of the process; $20 \%$ "solution $\# 2$ " and $80 \%$ "solution \#3" at 20 min; 30\% "solution \#2" and 70\% "solution \#3" at $25 \mathrm{~min} ; 40 \%$ "solution \#2" and 60\% "solution \#3" at $30 \mathrm{~min} ; 80 \%$ "solution \#2" and 20\% "solution \#3" at $35 \mathrm{~min}$; and additional 5 min of equilibration with $100 \%$ "solution $\# 1$ " till the end of the measurement.

A single-factor analysis of variances was performed at 95\% significance level after proving that variances are equal across groups (Bartlett's test). In each case where the differences of variances were significant Tukey-test was run at $95 \%$ and $99 \%$ significance level.

\section{Results and discussion}

The initial $1200 \mathrm{mg} \mathrm{l}^{-1}$ polyphenolics concentration decreased by approx. 100-200 $\mathrm{mg} \mathrm{l}^{-1}$ by the end of the fermentation. The amount of polyphenols was the lowest in the solution fermented with " $A$ " yeast (exactly $1000 \mathrm{mg} \mathrm{l}^{-1}$ ), in the other samples concentrations from 1085 to $1114.5 \mathrm{mg} \mathrm{l}^{-1}$ were measured. The highest value was found in the "B" sample. The statistical calculations showed that the polyphenol content did not depend on whether the fermentation was spontaneous or it was conducted with yeast inoculation, and so we could not discover any differences between the polyphenol uses of the examined commercial yeasts (Fig. 1). The data confirm the results of a former publication of BAUTISTA-OrTín and collegues (2007), which shows that the polyphenol content of spontaneously and commercial yeast fermented wines do not present great differences in every vintage.

Also the leucoanthocyanin and catechin content (Fig. 1) in the samples decreased by the end of the fermentation compared to the initial concentrations. The statistical test did confirm that neither the leucoanthocyanin, nor the catechin content development were different in the samples. The highest leucoanthocyanin content was achieved by the " $\mathrm{C}$ " yeast, the lowest 
concentrations were found for the " $\mathrm{A}$ " and " $\mathrm{D}$ " yeasts. The highest catechin content was produced with the "B" yeast; the catechin content of the spontaneously fermented sample was nearly the same. The lowest catechin content was measured in the "D" sample.

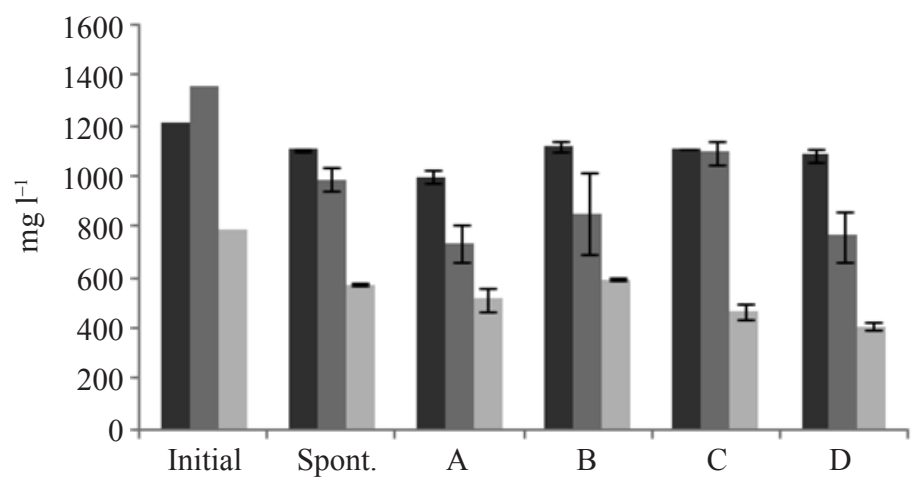

Fig. 1. Total polyphenolics, leucoanthocyanins, and catechins in the model composition before and after fermentation (Initial: model solution before fermentation; Spont.: spontaneously fermented model solution; A, B, C, and D: model solution fermented by A, B, C, and D commercial yeasts). $\mathbf{\square}$ : Total polyphenolics;

$\square$ : leucoanthocyanins; $\square$ : catechins

Significant differences were observed in the spectrophotometric detected total anthocyanin values. The highest concentration was observed with the spontaneous yeast fermentation with $208.5 \mathrm{mg} \mathrm{l}^{-1}$, which value was significantly higher than all the other yeast fermentations $(\alpha=0.01)$. The lowest value was measured in the "A" sample $\left(174.5 \mathrm{mg} \mathrm{l}^{-1}\right)$ (Fig. 2A). These results may be explained by the fact that the spontaneously fermented sample had the lowest sediment content and higher sediment contents were found in all commercial yeast fermented samples at the end of the fermentation. There were no statistically significant differences in the anthocyanin contents of the "B", " $C$ ", and "D" samples, however, the anthocyanin content of the "A" sample was significantly lower than that of the spontaneous and "C" samples $(\alpha=0.01)$, and than the "B" and " $\mathrm{D}$ " yeast fermented models $(\alpha=0.05)$. The spectrophotometric measurements showed that higher anthocyanin concentration might be achieved by spontaneous fermentation.
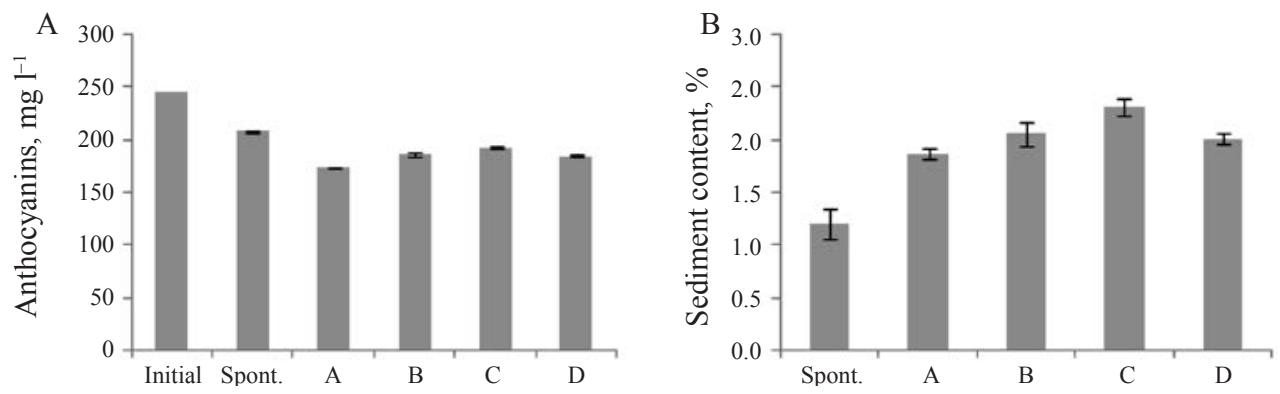

Fig. 2. Total anthocyanin content (A) and sediment content (B) in the model composition before and after fermentation (for explanation of abbreviations see Fig. 1) 
Although the anthocyanin determination discussed above showed that one does not necessarily benefit from the use of selected yeasts in terms of the amount of colour materials, the results of polymeric anthocyanins ratio measurements and the determination of the colour intensity and colour hue render the model more complex. The polymerisation of anthocyanin moieties helps to develop the wine colour stability. At the end of the fermentation, the polymeric molecules ratio significantly increased from the baseline in all five experimental solutions: while in the initial solution $33 \%$ of the anthocyanins were polymer molecules, after fermentation this proportion was $62 \%$ in the spontaneously fermented solution, $44 \%$ in sample "A", $49 \%$ in both samples "B" and " $C$ ", and 54\% in sample " $D$ ". The high value detected in the spontaneously fermented sample refers to a significant polymerization and this predicts the precipitation of pigments. Statistically the polymeric anthocyanins ratio was significantly higher in the spontaneous fermented sample as compared to " $\mathrm{A}$ ", "B", and "C" solutions $(\alpha=0.05)$, but no statistical differences were found among the four commercial yeast fermented samples, and between the " $\mathrm{D}$ " and the spontaneous sample either.

Examining the relationship between the anthocyanin concentration and the sediment quantity of the wine generated during fermentation (amount of sediment is presented in Fig. 2B) we get results apparently contradictory to practice. Relatively high decrease in the anthocyanin concentration is observed during red wine fermentation, since beside the colloidal precipitation of polymers and their deposition in the sediment, the adsorption of pigments is significant both in the solid-phase pomace (pulp, grape skins, and seeds) and on the yeast cell wall surface. During pressing a large amount of pigments leaves the pulp, and thus the anthocyanin loss is linked to the marc amount. The fermented wine is expected to retain pigments in higher concentration in batches pressed with more juice, so which have smaller marc and sediment content. But in our recent experiments we found that higher anthocyanin content was combined with higher sediment amounts in the commercial yeast fermented samples. However, we have to consider that the model solution did not contain solid phase pomace components, so the adsorption of anthocyanins have been only possible on the surface of yeast cells, so in the case of fermenting a model solution we cannot talk about the classic pigment decreasing during red wine fermentation.

The initial concentration of the monomer anthocyanins was $180 \mathrm{mg} \mathrm{l}^{-1}$ in the model solution, which decreased about to one third untill the end of fermentation. Based on the chromatographic results, the anthocyanin monomer concentration did not differ significantly in the five samples (Fig. 3). The lowest value was measured in the simultaneous fermented sample with $58.1 \mathrm{mg} \mathrm{l}^{-1}$ and sample "B" had practically the same amount $\left(59.3 \mathrm{mg} \mathrm{l}^{-1}\right)$. The anthocyanin monomers concentration of the " $\mathrm{A}$ " and " $\mathrm{C}$ " samples were similar (87.7 and $89.2 \mathrm{mg} \mathrm{l}^{-1}$ ), sample "D" possessed $66.7 \mathrm{mg} \mathrm{l}^{-1}$ anthocyanin monomers. In the initial solution as well as in the fermented models malvidine-3-monoglycoside was the typical monomer (Fig. 4). Its concentration was the lowest in the spontaneously fermented sample, and the highest in sample "C". The difference is significant between the two samples at $\alpha=0.05$. The concentration of each monomer anthocyanins decreased during fermentation.

The ratio of the acylated anthocyanin derivatives in the total quantity of anthocyanin monomers was the highest in sample "A" (35\%); similar ratio was detected in the spontaneous fermented sample (38\%). The ratios in the "B", "C", and " $D$ " samples were similar to each other $(27 \%, 30 \%$, and $30 \%$, respectively). Because of the relatively large standard deviations the acylated anthocyanins proportion of the five samples did not show significant differences. The composition of the model solutions did not allow to determine whether the acylated 


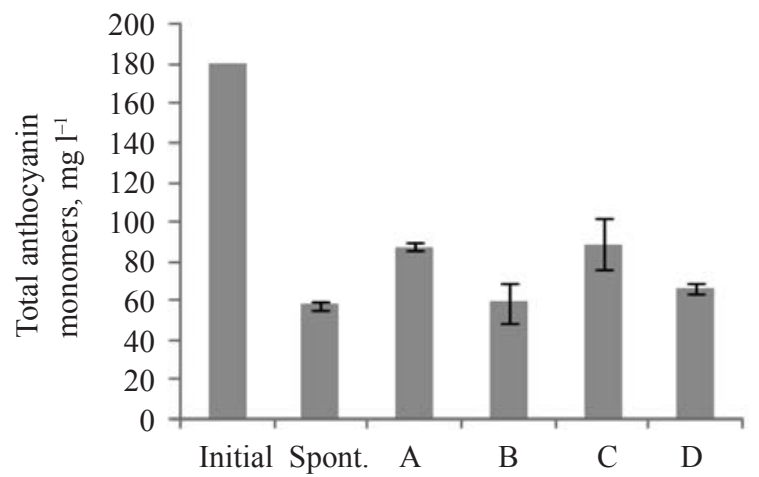

Fig. 3. Total amount of LC-detected anthocyanin monomers in the model composition before and after fermentation (for explanation of abbreviations see Fig. 1)

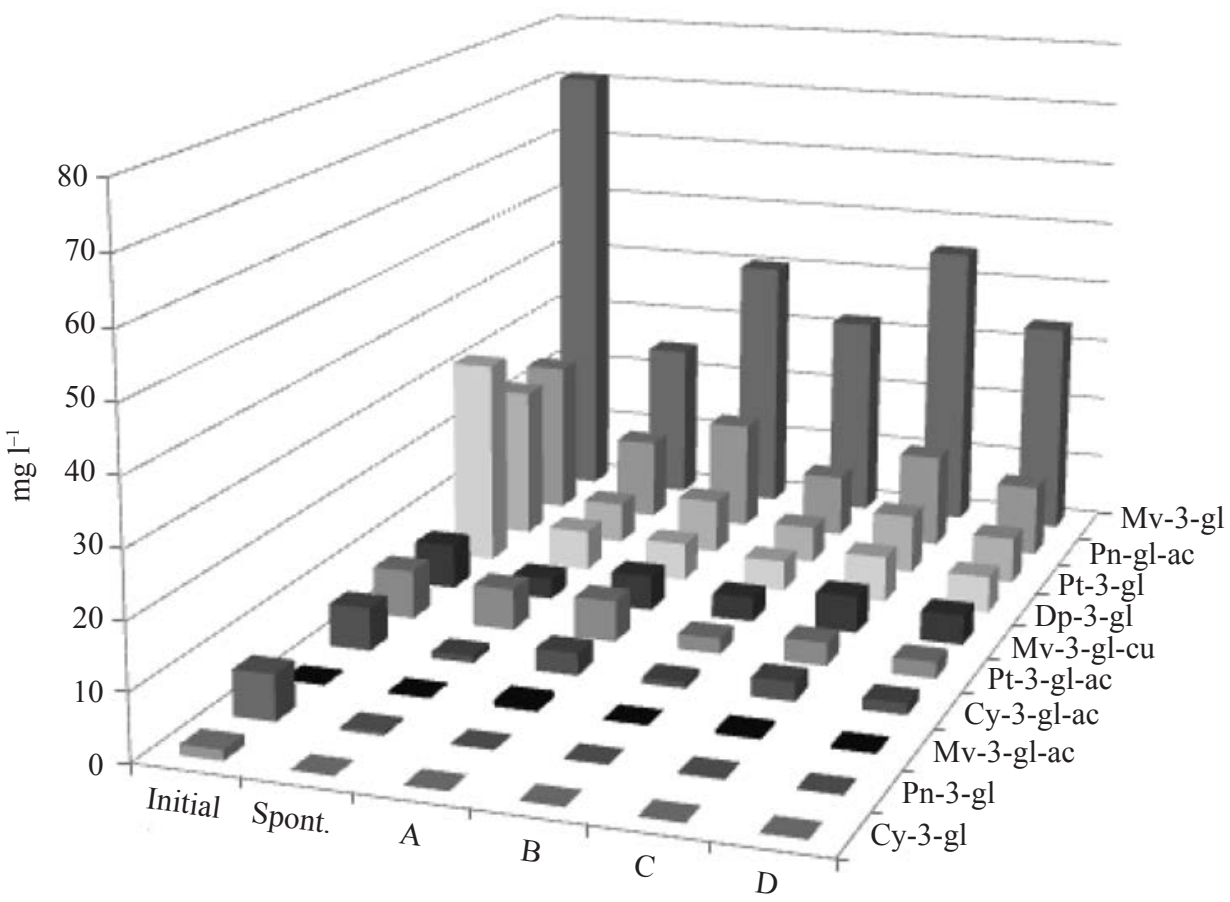

Fig. 4. Anthocyanin monomer profile of the model composition before and after fermentation (for explanation of abbreviations see Fig. 1)

anthocyanins have a higher affinity to settle down in the sediment as the results of MORATO and colleagues (2003) show.

The colour intensity of the samples ranged from 1.50 to 1.75 at the end of the fermentation. The lowest colour index was measured in the spontaneous fermented sample (1.50), while in commercial yeast fermented samples the colour intensity was 1.70 (in the "A" and the "D" sample) and 1.75 (in the "B" and the "C" sample). These results are in 
accordance with those of BAUTISTA-ORTín and colleagues (2007), but the statistical calculations show all five samples as identical. The colour hue of the spontaneous sample refers to browning, and its value of 1.08 proved to be significantly higher than the colour hue values of all four commercial yeast fermented samples $(0.92,0.95,0.95$, and 0.91$)$. The " $\mathrm{A}$ ", " $\mathrm{B}$ ", "C", and "D" samples tended to brown, but a high colour tone value was also characteristic of the initial solution, so the colour tone of the yeast inoculated samples did not change during fermentation. We note that the samples were not treated with sulphurous acid.

\section{Conclusions}

As a summary of our results, we found that inoculation with the tested commercial yeast strains is mainly advantageous compared to the spontaneous fermentation in respect of the quantitative development of components, which are responsible for red wine colour development and stability (polyphenolics, anthocyanin monomers), and of the colour characteristics (ratio of polymerisation, colour intensity, and colour hue). Differences were discovered regarding individual commercial yeasts, primarily in the anthocyanin content of the fermented product.

\section{References}

Bautista-Ortín, A.B., Romero-Cascales, I., Fernández-Fernández, J.I., López-Roca, J.M. \& Gómez-Plaza, E. (2007): Influence of the yeast strain on Monastrell wine colour. Innov. Fd Sci. Emerging Technol., 8, 322-328.

Chassagne, D., Vernizeau, S., Nedjma, M. \& Alexandre, H. (2005): Hydrolysis and sorption by Saccharomyces cerevisiae strains of Chardonnay grape must glycosides during fermentation. Enzyme Microbial Technol., 37 , $212-217$.

Cuinier, C. (1988): Influence des levures sur les composés phénoliques du vin. Bull. O.I.V., 61, 596-601.

Di Stefano, R., Borsa, D. \& Gentilini, N. (1994): Estrazione degli antociani dalle bucce dell'uva durante la fermentazione (Extraction of anthocyanins from the grape berry during fermentation). L'Enotecnico, 30, 75-83.

FLeEt, G.H. (1999): Microorganisms in food ecosystems. Int. J. Fd Microbiol., 50, 101-117.

KÁLlAY, M. \& TuSNÁDY, E. (2001): Néhány kékszőlő és vörösbor színanyag-összetételének vizsgálata HPLC-vel. (Colour pigment composition analysis by HPLC of some red grapes and red wines.) Élelmezési Ipar, 55, 196-200.

Medina, K., Boido, E., Dellacassa, E. \& Carrau, F. (2005): Yeast interactions with anthocyanins during red wine fermentation. Am. J. Enol. Vitic., 56, 104-109.

Morato, A., Gómez-Cordovés, M.C., Suberviola, J., Bartolomé, B., Colomo, B. \& SuÁrez, J.A. (2003): Adsorption of anthocyanins on yeast cell walls during the fermentation of red wines. J. Agric. Fd Chem., 51, 4048-4088.

Revilla, e., García-Beneytez, E., Cabello, F., Martín-Ortega, G. \& Ryan, J.M. (2001): Value of high-performance liauid chromatographic analysis of anthocyanins in the differentiation of red grape cultivars and red wines made from them. J. Chromatogr. A, 915, 53-60.

Ribereau-Gayon, P. \& Stonestreet, E. (1965): Determination of anthocyanins in red wine. Bull. Soc. Chim. France, 9, 49-52.

Sidari, R., Postorino, S., Caparello, A. \& Caridi, A. (2007): Evolution during wine aging of colour and tannin differences induced by wine starters. Ann. Microb., 57, 197-201

Singleton, V.L. \& Rossi, J. (1965): Colorimetry of total phenolics with phosphomolybdic-phosphotungstic acid reagents. Am. J. Enol. Vitic., 16, 144-158. 